\title{
The Comparative Risk Assessment for alcohol as part of the Global Burden of Disease 2010 Study: What changed from the last study?
}

\section{Editorial}

In December 2012, the new results of the Comparative Risk Assessment (CRA) for alcohol within the Global Burden of Disease and Injury (GBD) Study 2010 were presented at a joint meeting of the GBD Group and the journal Lancet at the Royal Society in London (Lim et al., 2012). At first glance, there do not appear to be many changes to alcohol consumption as a risk factor for death and disability: it is identified as the third most important risk factor, as it was in the last CRA (World Health Organization, 2009). The burden of disease attributable to alcohol had increased, compared to the 2004 estimate (Rehm, Mathers et al., 2009), but this could be due to an increase in global population, or to variations in the methodologies behind the 2004 and 2010 estimates.

On further reflection, however, it is apparent that a great deal has changed, in terms of both the overall ordering of risk factors and the alcohol findings. Between 2004 and 2010, the most important risk factors changed from childhood underweight and unsafe sex to high blood pressure and tobacco smoking (including passive smoking), reflecting the increasing importance of non-communicable disease in the global picture (Lim et al; World Health Organization, 2011). And if 1990 is compared with 2010 using the same methodology, the impact of alcohol consumption did increase, in terms of both absolute and relative figures for burden of disease (Lim et al., 2012).

What explains the change in the contribution of alcohol consumption to the burden of disease over the past 20 years, and how have the methodologies used to measure this burden changed over the last 10 years? Let us start with the methodological changes which may explain the increase from the $2000^{1}$ (Rehm et al., 2003; Rehm et al., 2004) to the 2010 CRA (Lim et al., 2012). These changes are quite substantial. First, new disease categories have been identified since 2000 as causally attributable to alcohol. For instance, the International Agency for Research on Cancer conducted a comprehensive review meeting on alcohol consumption in 2007, and added breast cancer and colorectal cancers to the list of cancers causally related to alcohol (Baan et al., 2007; International Agency for Research on Cancer, 2010, 2012). While the 2000 CRA

1 The 2004 CRA used the alcohol-attributable fractions of the 2000 CRA, and thus cannot be considered an independent CRA. had already included breast cancer, based on substantial scientific evidence already documented by that point (Rehm et al., 2004), much of the research on colorectal cancer is more recent, including a large-scale epidemiological study in eight European countries with more than 350,000 participants (International Agency for Research on Cancer, 2012; Schütze et al., 2011). In addition, it had become clearer that ethanol is the main carcinogenic ingredient in alcoholic beverages (Lachenmeier, Przybylski, \& Rehm, 2012). Meanwhile, a "residual" category of cancer (Other neoplasms GBD category: IIB) was removed from the list, because there is currently no way to quantify the impact of alcohol in this category (Rehm, Baliunas et al., 2010).

Then there were changes resulting from the inclusion of additional disease categories only recently added by the GBD group, such as pancreatitis and atrial fibrillation. For both of these categories, the causal relation to alcohol consumption had been recognized for some time, but the quantification of risk relations was missing and had to be established (Irving, Samokhvalov, \& Rehm, 2009; Samokhvalov, Irving, \& Rehm, 2010a). However, the biggest change in alcohol-attributable disease categories was the addition of infectious disease. While the link between alcohol consumption, especially heavy consumption, and infectious diseases has long been known (Rush, 1785), there were questions about causality and quantification of risk relations (Parry, Rehm, Poznyak, \& Room, 2009). These questions were relatively easy to address for tuberculosis (Lönnroth, Williams, Stadlin, Jaramillo, \& Dye, 2008; Rehm, Samokhvalov et al., 2009) and pneumonia (Samokhvalov, Irving, \& Rehm, 2010b); the resulting attributable fractions are presented in this issue (Shield, Samokhvalov, \& Rehm, 2013). However, establishing causality was more problematic for HIV/AIDS and sexually transmitted infections, where active behavior plays a necessary role in transmission pathways (Shuper et al., 2010). The main counter-argument against causality was that a third factor-for instance a tendency towards risk taking, as a personality trait-could influence both alcohol consumption and unsafe sex as the main transmission pathway. While experimental research could establish that there is a causal impact of alcohol on intention for unsafe sex (Rehm, Shield, Joharchi, \& Shuper, 2012), the quantification of risk relations could not be 
undertaken within the temporal frame of the CRA. Clearly it is not the case that alcohol caused HIV transmission, or caused progression of the disease, in every case of HIV/AIDS associated with alcohol consumption (Baliunas, Rehm, Irving, \& Shuper, 2010); therefore, future research must strive to find a methodology to quantify the causal proportion. As a consequence, at this time, only a part of the disease burden associated with HIV/AIDS can be calculated as attributable to alcohol consumption-namely, the part due to drinking-related lack of adherence to antiretroviral medication. These results, not yet included in the CRA for 2010 (Lim et al., 2012), are presented in this issue (Shield, Shuper, Gmel, \& Rehm, 2013). A more detailed explanation and discussion of the assumptions and methodology of these estimates can be found in a contribution by Gmel and colleagues (Gmel, Shield, \& Rehm, 2011).

Problems with quantification of alcohol-attributable disease burden continue to exist for mental disorders. Consider alcohol consumption and depression as an example. Clearly, alcohol consumption and alcohol use disorders can make a causal contribution to depression (Rehm et al., 2004). There is even a separate category in the Diagnostic and Statistical Manual of Mental Disorders for substanceinduced depression, in both DSM-IV (American Psychiatric Association, 2000) and the proposed DSM-V (http://www.dsm5.org/pages/default.aspx). But the reverse causality is also true, and there may be additional factorssuch as genetic vulnerability-for both depression and heavy alcohol consumption or alcohol use disorders. Similar arguments could be made for anxiety and other mental disorders. Thus, the results of the CRA clearly underestimate the indirect effect of alcohol through mental disorders, because these estimates exclude all mental disorders due to alcohol consumption except for alcohol use disorders. In 2000, the impact of consumption on depression was estimated (Rehm et al., 2004), but it was decided that the algorithm used was not sufficiently validated to re-use it in this round of the GBD.

Other differences concern the calculation of injury and the determination of disability weights. For injuries, the determination of attributable fractions was previously linked to a seminal study in 2000/2004 and adjusted based on exposure dimensions (English et al., 1995; Rehm et al., 2004). In the new CRA, a formula was developed that was based directly on average drinking and episodic heavy drinking and their relative risks (Shield, Gmel, Patra, \& Rehm, 2012), drawing on analyses by Taylor, Rehm and Colleagues (Taylor et al., 2010; Taylor, Shield, \& Rehm, 2011). The new disability weights (for a general overview, see Rehm \& Frick, 2010) were established based on an empirical study.

In addition to the methodological differences between the GBD 2000/2004 and the GBD 2010 in calculating the alcohol-attributable burden, there were other differences concerning the estimation of exposure and its uncertainty (for details see Rehm, Klotsche, \& Patra, 2007 for the earlier GBDs; and Rehm, Kehoe et al., 2010, as well as Gmel, Shield, Frick et al., 2011 for the GBD 2010). Most importantly, the triangulation between survey results and per capita consumption changed as a result of recent research (Kehoe, Gmel, Shield, Gmel, \& Rehm, 2012).

The changes between GBD 2000/2004 and GBD 2010 make these efforts difficult to compare in a meaningful way. This was one of the reasons why the current GBD study group undertook the task of making new estimates for 1990 which were comparable to those from 2010. The results show that alcohol consumption has increased in impact as a risk factor (Lim et al., 2012) from rank 6 in 1990 to rank 3 in 2010. What are the reasons for this change? First, more alcohol was consumed in 2010 than in 1990. Second, the distribution of disease changed, and the disease categories more highly attributable to alcohol increased in relative weight. This is true for noncommunicable chronic diseases (cancer, cardiovascular disease, liver cirrhosis; see (Parry, Patra, \& Rehm, 2011) and (Room, Rehm, \& Parry, 2011)), and for injuries, almost all of which have a strong link to alcohol consumption (Rehm, Popova, \& Patra, 2009; Shield et al., 2012). It is also true for mental disorders, although the contribution of alcohol use to these is underestimated, for the reasons described above.

The difference between 1990 and 2010 will thus persist, even when the numbers from Lim et al. (2012) will be corrected in one of the next issues of Lancet, because the relationship with ischaemic heart disease had been overestimated (see Roerecke \& Rehm, 2010; 2011; 2012; for the correct relationships).

Both of these trends towards an increase in alcohol's contribution to the burden of disease are also expected to continue, unless there are interventions. The World Health Organization has thus started to implement a global strategy to reduce the harmful use of alcohol, with taxation and pricing policies figuring prominently (World Health Organization, 2010). The third original contribution to this special section, from Bundit Sornpaisarn and colleagues (Sornpaisarn, Shield, Cohen, Schwartz, \& Rehm, 2012), is thus particularly pertinent, as it gives information on the effects of taxation in low- and middle-income countries, where the effects of alcohol consumption are the largest, both in absolute numbers (Lim et al., 2012), and relative to high income countries (Rehm, Anderson et al., 2009).

\section{Reference}

American Psychiatric Association. (2000). Diagnostic and statistical manual of mental disorders, 4th edition, primary care. Washington, DC, United States: American Psychiatric Association.

Baan, R., Straif, K., Grosse, Y., Secretan, B., El Ghissassi, F., Bouvard, V., . . . On behalf of the WHO International Agency for Research on Cancer Monograph Working Group. (2007). Carcinogenicity of alcoholic beverages. Lancet Oncology, 8, 292-293.

Baliunas, D., Rehm, J., Irving, H., \& Shuper, P. (2010). Alcohol consumption and risk of incident human 
immunodeficiency virus infection: A meta-analysis. International Journal of Public Health, 55, 159-166.

English, D., Holman, C., Milne, E., Winter, M., Hulse, G., Codde, G., . . . Ryan, G. (1995). The quantification of drug caused morbidity and mortality in Australia 1995. Canberra, Australia: Commonwealth Department of Human Services and Health.

Gmel, G., Jr, Shield, K. D., Frick, H., Kehoe, T., Gmel, G., \& Rehm, J. (2011). Estimating uncertainty of alcoholattributable fractions for infectious and chronic diseases. BMC Medical Research Methodology, 11, 48.

Gmel, G., Sr., Shield, K., \& Rehm, J. (2011). Developing a methodology to derive alcohol-attributable fractions for HIV/AIDS mortality based on alcohol's impact on adherence to antiretroviral medication. Population Health Metrics, 9, 5.

International Agency for Research on Cancer. (2010). IARC Monographs on the evaluation of carcinogenic risks to humans: Alcohol consumption and ethyl carbamate. Lyon, France: International Agency for Research on Cancer.

International Agency for Research on Cancer. (2012). A review of human carcinogens: Personal habits and indoor combustions (Vol. 100E). Lyon, France: Author.

Irving, H. M., Samokhvalov, A., \& Rehm, J. (2009). Alcohol as a risk factor for pancreatitis. A systematic review and meta-analysis. Journal of the Pancreas, 10, 387-392.

Kehoe, T., Gmel, G., Jr., Shield, K., Gmel, G., Sr., \& Rehm, J. (2012). Modelling alcohol consumption as a distribution and determining the impact of the distribution on estimated alcohol-attributable harms. Population Health Metrics, 10, 6.

Lachenmeier, D. W., Przybylski, M. C., \& Rehm, J. (2012). Comparative risk assessment of carcinogens in alcoholic beverages using the margin of exposure approach. International Journal of Cancer, 131, E995E1003. doi: 10.1002/ijc.27553

Lim, S. S., Vos, T., Flaxman, A. D., Danaei, G., Shibuya, K., Adair-Rohani, H., . . . Ezzati, M. (2012). A comparative risk assessment of burden of disease and injury attributable to 67 risk factors and risk factor clusters in 21 regions, 1990-2010: A systematic analysis for the Global Burden of Disease Study 2010 Lancet 380, 2224-2260.

Lönnroth, K., Williams, B., Stadlin, S., Jaramillo, E., \& Dye, C. (2008). Alcohol use as a risk factor for tuberculosis: A systematic review. BMC Public Health, 8, 289.

Parry, C., Patra, J., \& Rehm, J. (2011). Alcohol consumption and non-communicable diseases: Epidemiology and policy implications. Addiction, 106, 1718-1724.

Parry, C. D. H., Rehm, J. R., Poznyak, V., \& Room, R. (2009). Alcohol and infectious diseases: Are there causal linkages? Addiction, 104, 331-332.

Rehm, J., Anderson, P., Kanteres, F., Parry, C. D., Samokhvalov, A. V., \& Patra, J. (2009). Alcohol, social development and infectious disease. Toronto, Canada: Centre for Addiction and Mental Health.
Rehm, J., Baliunas, D., Borges, G. L. G., Graham, K., Irving, H. M., Kehoe, T., . . . Taylor, B. (2010). The relation between different dimensions of alcohol consumption and burden of disease: An overview. Addiction, 105, 817-843.

Rehm, J., \& Frick, U. (2010). Valuation of health states in the U.S. study to establish disability weights: Lessons from the literature. International Journal of Methods in Psychiatric Research, 19, 18-33.

Rehm, J., Kehoe, T., Gmel, G., Stinson, F., Grant, B., \& Gmel, G. (2010). Statistical modeling of volume of alcohol exposure for epidemiological studies of population health: the example of the US. Population Health Metrics, 8, 3.

Rehm, J., Klotsche, J., \& Patra, J. (2007). Comparative quantification of alcohol exposure as risk factor for global burden of disease. International Journal of Methods in Psychiatric Research, 16, 66-76.

Rehm, J., Mathers, C., Popova, S., Thavorncharoensap, M., Teerawattananon, Y., \& Patra, J. (2009). Global burden of disease and injury and economic cost attributable to alcohol use and alcohol use disorders. Lancet, 373, 2223-2233. doi: 10.1016/S01406736(09)60746-7

Rehm, J., Popova, S., \& Patra, J. (2009). Alcoholattributable injury in a global perspective. In C. J. Cherpitel, G. Borges, N. Giesbrecht, D. Hungerford, M. Peden, V. Poznyak, R. Room \& T. Stockwell (Eds.), Alcohol and injuries. Emergency department studies in an international perspective Geneva, Switzerland: World Health Organization.

Rehm, J., Room, R., Monteiro, M., Gmel, G., Graham, K., Rehn, N., . . . Jernigan, D. (2003). Alcohol as a risk factor for global burden of disease. European Addiction Research, 9, 157-164.

Rehm, J., Room, R., Monteiro, M., Gmel, G., Graham, K., Rehn, N., . . . Jernigan, D. (2004). Alcohol Use. In M. Ezzati, A. D. Lopez, A. Rodgers \& C. J. L. Murray (Eds.), Comparative quantification of health risks: global and regional burden of disease attributable to selected major risk factors (Vol. 1, pp. 959-1109). Geneva, Switzerland: World Health Organization.

Rehm, J., Samokhvalov, A. V., Neuman, M. G., Room, R., Parry, C. D., Lönnroth, K., . . Popova, S. (2009). The association between alcohol use, alcohol use disorders and tuberculosis (TB). A systematic review. BMC Public Health, 9, 450.

Rehm, J., Shield, K. D., Joharchi, N., \& Shuper, P. A. (2012). Alcohol consumption and the intention to engage in unprotected sex: Systematic review and meta-analysis of experimental studies. Addiction, 107, 51-59.

Roerecke, M., \& Rehm, J. (2010). Irregular heavy drinking occasions and risk of ischemic heart disease: A systematic review and meta-analysis. American Journal of Epidemiology, 171, 633-644.

Roerecke, M., \& Rehm, J. (2011). Ischemic heart disease mortality and morbidity in former drinkers: A metaanalysis. American Journal of Epidemiology, 73, 245258.

Roerecke, M., \& Rehm, J. (2012). The cardioprotective association of average alcohol consumption and 
ischaemic heart disease: A systematic review and meta-analysis. Addiction, 107, 1246-60.

Room, R., Rehm, J., \& Parry, C. (2011). Alcohol and noncommunicable diseases (NCDs): Time for a serious international public health effort. Addiction, 106, 1547-1548.

Rush, B. (1785). An inquiry into the effects of ardent spirits upon the human body and mind: With an account of the means of preventing, and of the remedies for curing them. 8th edition. Reprint. Exeter, NH, United States: Richardson.

Samokhvalov, A. V., Irving, H. M., \& Rehm, J. (2010a). Alcohol as a risk factor for atrial fibrillation: A systematic review and meta-analysis. European Journal of Cardiovascular Prevention \& Rehabilitation, 17, 706-712.

Samokhvalov, A. V., Irving, H. M., \& Rehm, J. (2010b). Alcohol consumption as a risk factor for pneumonia: Systematic review and meta-analysis. Epidemiology and Infection, 138, 1789-1795.

Schütze, M., Boeing, H., Pischon, T., Rehm, J., Kehoe, T., Gmel, G., . . . Bergmann, M. M. (2011). Alcohol attributable burden of incidence of cancer in eight European countries based on results from prospective cohort study. British Medical Journal, 342, d1584.

Shield, K. D., Gmel, G., Jr., Patra, J., \& Rehm, J. (2012). Global burden of injuries attributable to alcohol consumption in 2004: A novel way of calculating the burden of injuries attributable to alcohol consumption. Population Health Metrics, 10, 9.

Shield, K. D., Samokhvalov, A. V., \& Rehm, J. (2013). Global burden of tuberculosis and lower respiratory infections attributable to alcohol consumption in 2004. International Journal of Alcohol and Drug Research, 2, 11-18. doi: 10.7895/ijadr.v2i1.49

Shield, K. D., Shuper, P. A., Gmel, G. Jr., \& Rehm, J. (2013). Global Burden of HIV/AIDS in 2004 resulting from alcohol attributable non-adherence to medication regimes. International Journal of Alcohol and Drug Research, 2, 19-44. doi: 10.7895/ijadr.v2il.52

Shuper, P. A., Neuman, M., Kanteres, F., Baliunas, D., Joharchi, N., \& Rehm, J. (2010). Causal considerations on alcohol and HIV/AIDS: A systematic review. Alcohol and Alcoholism, 45, 159166.

Sornpaisarn, B., Shield, K., Cohen, J., Schwartz, R., \& Rehm, J. (2013). Elasticity of alcohol consumption, alcohol-related harms, and drinking initiation in lowand middle-income countries: A systematic review and meta-analysis. International Journal of Drug and Alcohol Research, 2, 45-58. doi: 10.7985/ijadr.v2il.50

Taylor, B., Irving, H. M., Kanteres, F., Room, R., Borges, G., Cherpitel, C., . . . Rehm, J. (2010). The more you drink, the harder you fall: A systematic review and meta-analysis of how acute alcohol consumption and injury or collision risk increase together. Drug and Alcohol Dependence, 110, 108-116.

Taylor, B., Shield, K., \& Rehm, J. (2011). Combining best evidence: A novel method to calculate the alcoholattributable fraction and its variance for injury mortality. BMC Public Health, 11, 265.
World Health Organization. (2009). Global Health Risks. Mortality and burden of disease attributable to selected major risks. Geneva, Switzerland: Author.

World Health Organization. (2010). Global strategy to reduce the harmful use of alcohol. Geneva, Switzerland: Author.

World Health Organization. (2011). Global status report on noncommunicable diseases 2010. Description of the global burden of NCDs, their risk factors and determinants. Geneva, Switzerland:: Author.

Jürgen Rehm, Ph.D.

Social and Epidemiological Research (SER) Department, Centre for Addiction and Mental Health, Toronto, Canada

Dalla Lana School of Public Health, University of Toronto, Canada

Department of Psychiatry, Faculty of Medicine, University of Toronto, Canada

Institute of Medical Science, University of Toronto, Canada

Technische Universitaet Dresden, Klinische Psychologie \& Psychotherapie, Dresden, Germany

Guilherme Borges, Ph.D.

National Institute of Psychiatry \& Metropolitan Autonomous University, Mexico City, Mexico

Gerhard Gmel, Ph.D.

Alcohol Treatment Centre, Lausanne University Hospital CHUV, Lausanne, Switzerland

Section Epidemiology and Statistics, Addiction Switzerland, Lausanne, Switzerland

Centre for Addiction and Mental Health, Toronto, Canada University of the West of England, Bristol, United Kingdom

Kathryn Graham, Ph.D.

Centre for Addiction and Mental Health, Toronto, Canada Department of Psychology, University of Western Ontario, London, Canada

Dalla Lana School of Public Health, University of Toronto, Toronto, Canada

National Drug Research Institute, Curtin University of Technology, Perth, Australia

Bridget Grant

National Institute on Alcohol Abuse and Alcoholism (NIAAA), National Institutes of Health, Rockville, USA

Charles Parry

Alcohol \& Drug Abuse Research Unit, Medical Research Council, Cape Town, South Africa

Department of Psychiatry, Stellenbosch University, Tygerberg, South Africa 
Vladimir Poznyak

World Health Organization Headquarters, Geneva, Switzerland

\section{Robin Room}

Centre for Alcohol Policy Research, Turning Point Alcohol \& Drug Centre, Fitzroy, Victoria, Australia;

Melbourne School of Population Health, University of Melbourne, Australia; Centre for Social Research on Alcohol \& Drugs, Stockholm University, Stockholm, Sweden 